Article

\title{
Archaeoastronomy: A Sustainable Way to Grasp the Skylore of Past Societies
}

\author{
Antonio César González-García ${ }^{1, *[1}$ and Juan Antonio Belmonte ${ }^{2}$ \\ 1 Instituto de Ciencias del Patrimonio, Incipit, Consejo Superior de Investigaciones Científicas, \\ Avda. de Vigo s/n, 15705 Santiago de Compostela, Spain \\ 2 Instituto de Astrofísica de Canarias \& Universidad de La Laguna, Calle Vía Láctea s/n, 38200 La Laguna, \\ Spain; jba@iac.es \\ * Correspondence: a.cesar.gonzalez-garcia@incipit.csic.es
}

Received: 8 March 2019; Accepted: 10 April 2019; Published: 14 April 2019

\begin{abstract}
If astronomy can be understood as the contemplation of the sky for any given purpose, we must realize that possibly all societies throughout time and in all regions have watched the sky. The why, who, how and when of such investigation is the pursuit of cultural astronomy. When the research is done with the archaeological remains of a given society, the part of cultural astronomy that deals with them is archaeoastronomy. This interdisciplinary field employs non-invasive techniques that mix methodologies of the natural sciences with the epistemology of humanities. Those techniques are reviewed here, providing an excellent example of sustainable research. In particular, we include novel research on the Bohí Valley Romanesque churches. The results provided go beyond the data. This is because they add new value to existing heritage or discovers new heritage due to the possible relationship to the spatial and temporal organization of past societies. For the case of the Bohí churches the results point to a number of peculiarities of these churches in a valley in the Pyrenees. This links these aspects to the ritual, practical and power sphere of past societies. A wonderful example of such links is the high mountain sanctuaries in Gran Canaria, where archaeoastronomy helps promoting a World Heritage candidacy.
\end{abstract}

Keywords: cultural astronomy; archaeoastronomy; field techniques; Bohí Romanesque churches; Canary Islands; landscape archaeology

\section{Introduction}

Far from being a particular version of the history of astronomy, or a specialized archaeometry, cultural astronomy is something else. Human knowledge can be specialized (i.e., medical, astronomical, etc.) but when such knowledge is used it becomes social and human, as society is the context where all that is human is produced and used. This is why we must ask for the sense of such uses. When we do this with respect to specialized knowledge, there appear research questions, data and methodologies that go beyond the expertise of the specialist on such knowledge. A social and human version of this knowledge is thus needed to answer those questions. In the case of the sky, such an approach is cultural astronomy.

There is one part of the humanities that focuses on the environment influence on human societies. However, there is only one discipline that deals with the relationship between those societies throughout history and the sky below they dwell, and this is what has been called astronomy in culture or rather cultural astronomy.

If a naïve and simple definition of astronomy could be sky-watching, then cultural astronomy is realizing that any society, present or past, has actually looked at the sky. This is why as astronomers we would like to know what they were watching. However, as cultural astronomers we want to 
understand how they generated, processed and used such knowledge. Hence, the focus is not in the celestial objects they identified but how those were understood and incorporated by that society from their cultural point of view.

Cultural astronomy thus tries to answer questions that go beyond astrophysical interest. It tries to understand how astronomical knowledge is generated in ancient, traditional and ancestral societies. How is such knowledge transmitted? What are the processes of social production, transference and diffusion of such astronomical knowledge? Was it invented by all societies independently? Or, on the contrary, were some basic principles (like the identification of solstices or equinoxes) generated in some cultures and later transmitted to others? Were 'primitive astronomers' some kind of 'artisans', i.e., a specific social group? Were they privileged? Or, was the astronomical lore simply produced in a general sense, without any concrete author? Other pertinent questions, such as what was the influence of the concept of the sky in the power relations or the structuration of society may also arise.

In a definition given by Stanislaw Iwaniszewski [1], cultural astronomy is the study of the relations between people's perception of the sky and the organization of different aspects of the social life. Such study, according to Edwin Krupp [2] includes several different topics: Calendars, practical observation, celestial cults and myths, symbolic representation of astronomical events, naming celestial objects, astronomical concepts or laws, the astronomical orientation of tombs, temples, sanctuaries and towns, traditional cosmology and the ceremonial use of astronomical traditions.

Cultural astronomy thus includes several other sub-disciplines, such as ethnoastronomy and astronomy in traditional and subsidiary societies (like pastoral groups, etc.), or archaeoastronomy. In this context, archaeoastronomy can be understood as the study of the orientation of buildings and their possible relationship to astronomical events. In short then, archaeoastronomy is the study of cultural astronomy through the material record, while ethnoastronomy would be the study of cultural astronomy via the ethnography of present day or past societies.

Cultural astronomy is a relatively new discipline that complements and deepens, from different points of view, the understanding of several other disciplinary fields. As examples to be considered we may count on: Landscape archaeology, understood in a broad sense, including the construction of spatial materiality in relation to the observation of astronomical phenomena [3]; the history of religions, from the orientation of sacred sites to the ritual conditioning of calendars; historic anthropology, understood as a holistic focus on human actions in the past, where cultural astronomy contributes by studying the different images of the cosmos in different societies. Finally, it could also be seen as a history of science as it studies the knowledge of the universe in different cultures and historical periods.

As with any other historical or archaeological data, archaeoastronomy pretends to shed light into the people in the past, and to do so we must do it by approaching the way of thinking of the society we deal with [4]. This means that the data and hypotheses advanced by cultural astronomy have to be supported on and by the archaeological, ethnographic or historical record [5].

In summary, cultural astronomy offers an increase in the understanding of cultural and archaeological heritage in two ways: It discovers 'new heritage' and provides new value to that already known or helps identifying heritage at risk (see Figure 1).

All in all, it should be noted that cultural astronomy is the way to get in contact with a basic heritage element: The one constituted by the materials, knowledge and values related to the observation of the sky. Cultural astronomy offers a way to gain access to a number of phenomena that otherwise would pass unnoticed. UNESCO has recognized such dimension in the category of Astronomical World Heritage Sites [6,7]. In the subsequent sections of the present paper we will focus on the sustainability of archaeoastronomical research. First we will present how this research is currently done, next we will introduce the results for a particular case study and, finally, we will focus on a qualitative example on how this research helps promoting a candidacy for a World Heritage Site. 


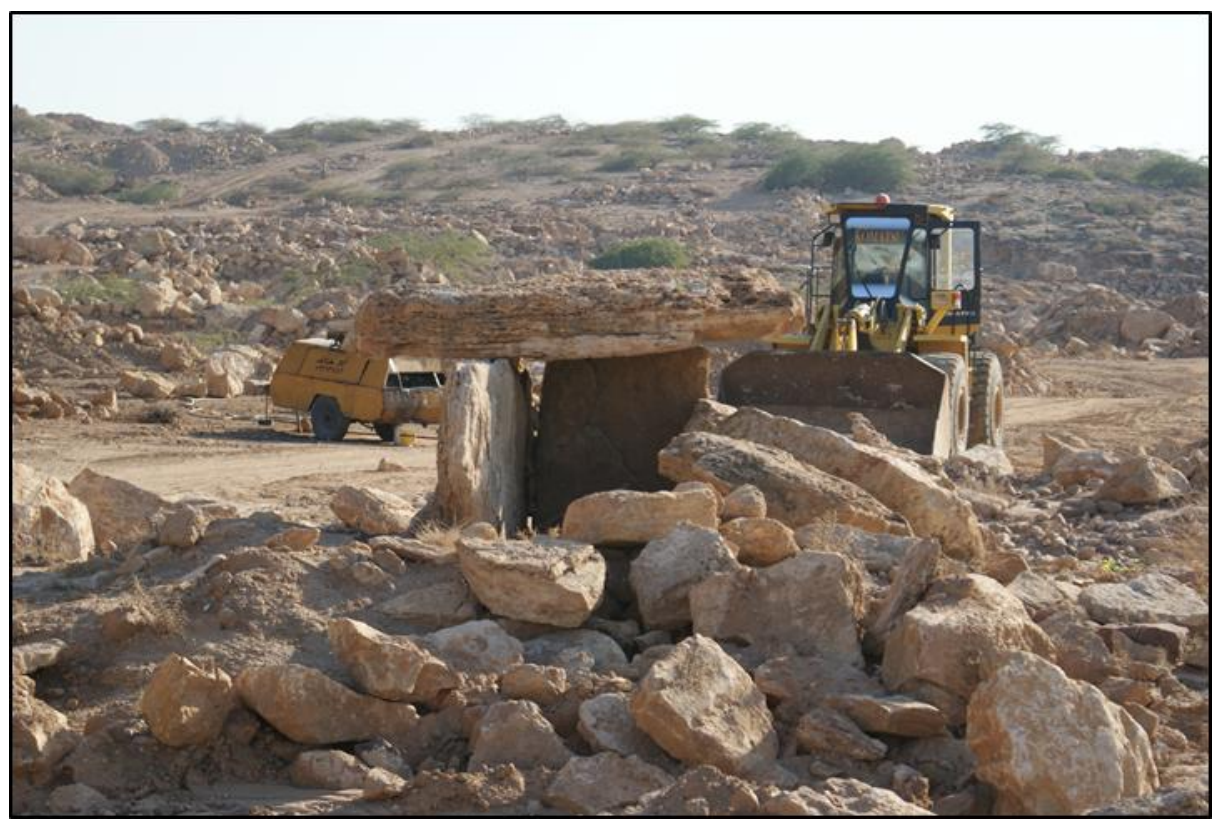

Figure 1. Archaeoastronomical fieldwork helps identify heritage at risk. This was the case with the Dahmiyeh dolmen field, one of the Bronze Age megalithic necropolises in Jordan studied by the authors [8]. These megalithic monuments of the local Bronze Age are built with a valuable travertine stone and were located next to the site where this material was obtained. A stone quarry now menaces this dolmen field and several dolmens are already being dismantled without compassion. (C) A.C. González-García.

\section{Sustainability of Archaeoastronomical Research}

According to Nature's website [9], sustainability is the ability to endure, for example, by exploiting resources in a way that does not deplete their availability for the future. We will use this definition as a working tool for the next paragraphs when presenting how archaeoastronomy does research and if this is done in a sustainable way. In other words, in such a way that may allow further data acquisition from the same site in the future. A final consideration on another aspect of the sustainability of archaeoastronomical research will be done at the conclusion section.

As indicated above, archaeoastronomy is done through the study of the archaeological record from the perspective of cultural astronomy. It is common lore that the conventional archaeological methodology is non-sustainable as it relies on the excavation and thus on the 'destruction' of the archaeological site. However, it is indeed true that nowadays there are a number of non-invasive techniques helping archaeology, such as different kinds of geophysical surveys, and some of them will be acknowledged and mentioned later on.

From this perspective, and having in mind the sustainability of research in archaeoastronomy, there are different levels open for consideration. For example, do we need excavation for doing research in archaeoastronomy? Are there any alternatives?

All these issues deal with the methodology employed to carryout data acquisition. In general, archaeoastronomical data are obtained through the visual inspection of the site of interest. Once a line of sight is defined for whatever reason (notably a symmetry line of a given building or the alignment of a number of artificial elements) our measuring device is situated either on top of that line of sight or closely parallel to it. Then two readings are usually recorded, the angle of this line with respect to true north (the azimuth) and the altitude of the horizon along that line of sight. Those two measurements together with the location of the observation point read through a GPS will facilitate the translation of these readings into astronomical measurements (see Figure 2; for a complete and detailed description of the measurement procedure see [10]). 


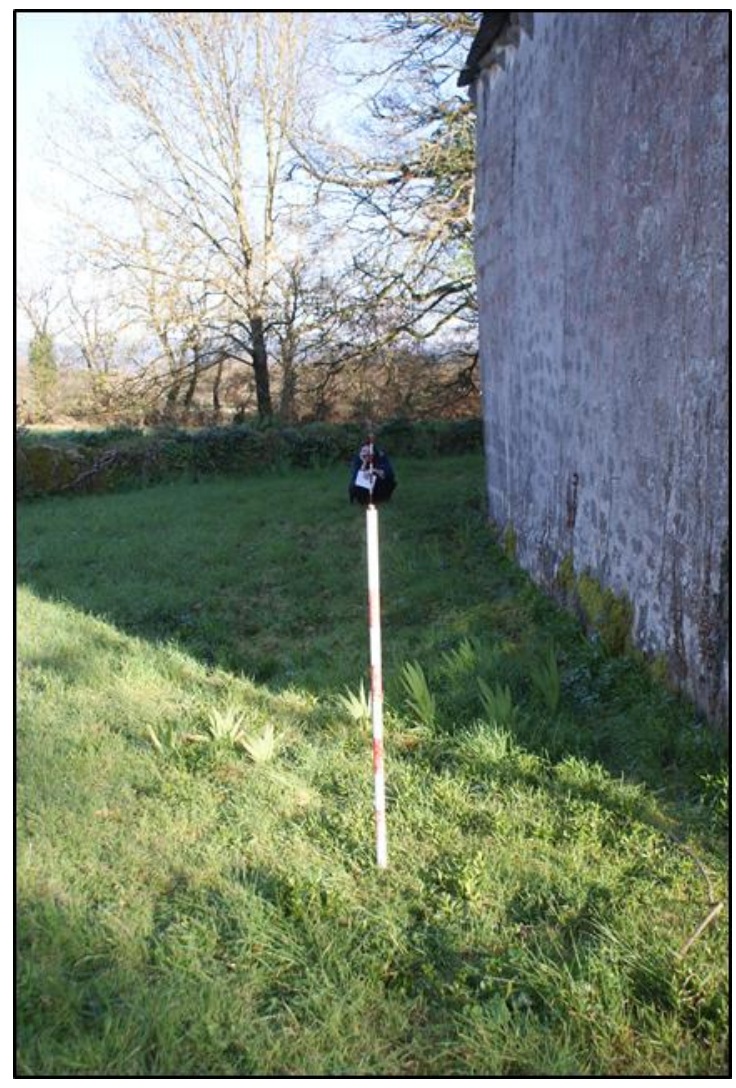

Figure 2. The data acquisition process in archaeoastronomy does not involve any kind of disturbance to the archaeological or heritage sites. The picture shows a common procedure for the measurement of a built structure, in this case a Romanesque church in Galicia, Spain. The technique involves deriving a parallel line to the wall to be measured with two rods. (C) A.C. González-García.

One other kind of data acquisition is done through the landscape inspection and measurement for the verification of potential landscape/heavenly relations. This is done by carefully inspecting the horizon observed from a particular site. There, singular directions, perhaps marked by other sites located at the horizon or by natural singular features such as notches or mountain peaks, could be linked to directions where interesting astronomical phenomena can be observed (see e.g., [11-13]).

In order to verify if the astronomical data is of any use at any archaeological site, one must be very careful. The pertinence of such data ought to be reckoned, making questions such as: Were astronomy or astral deities known to be important for the society we are dealing with? (see e.g., [14-17]). If we do not have any such information, as for prehistoric societies, either we can rely on solid interpretations of the iconography or we can try to proof the intentionality by performing statistical studies that may indicate the existence of orientation patterns that could only be explained by astronomical phenomena (see e.g., [18,19]).

As we can see, there is no need for an excavation or any other invasive technique within this procedure, so in principle the methodology per se is quite non-interventionist, nor harmful and thus sustainable. Another question is that to be able to define the measured line or the observation point we may need previously excavated structures, or not, if new techniques such as geo-radar are applied.

One key issue that we advocate archaeologists should incorporate to their excavation/prospection routine, as a standard procedure, is that of a horizon reconstruction or recording, which is seldom altered during the excavation process. This procedure can be as easy as taking a number of photographs, normally more than eight, to cover the $360^{\circ}$ visible from the prospection or excavation site. This would help the researcher to reconstruct the horizon in the laboratory, for instance using customary image treatment software, and then incorporating such landscape into planetarium software, such 
as Stellarium [20]. This will be useful to verify if there are interesting and/or important astronomical connections from that site. As we have argued, this does not necessarily take much time and the amount of data that can be provided is substantial (see Figure 3).

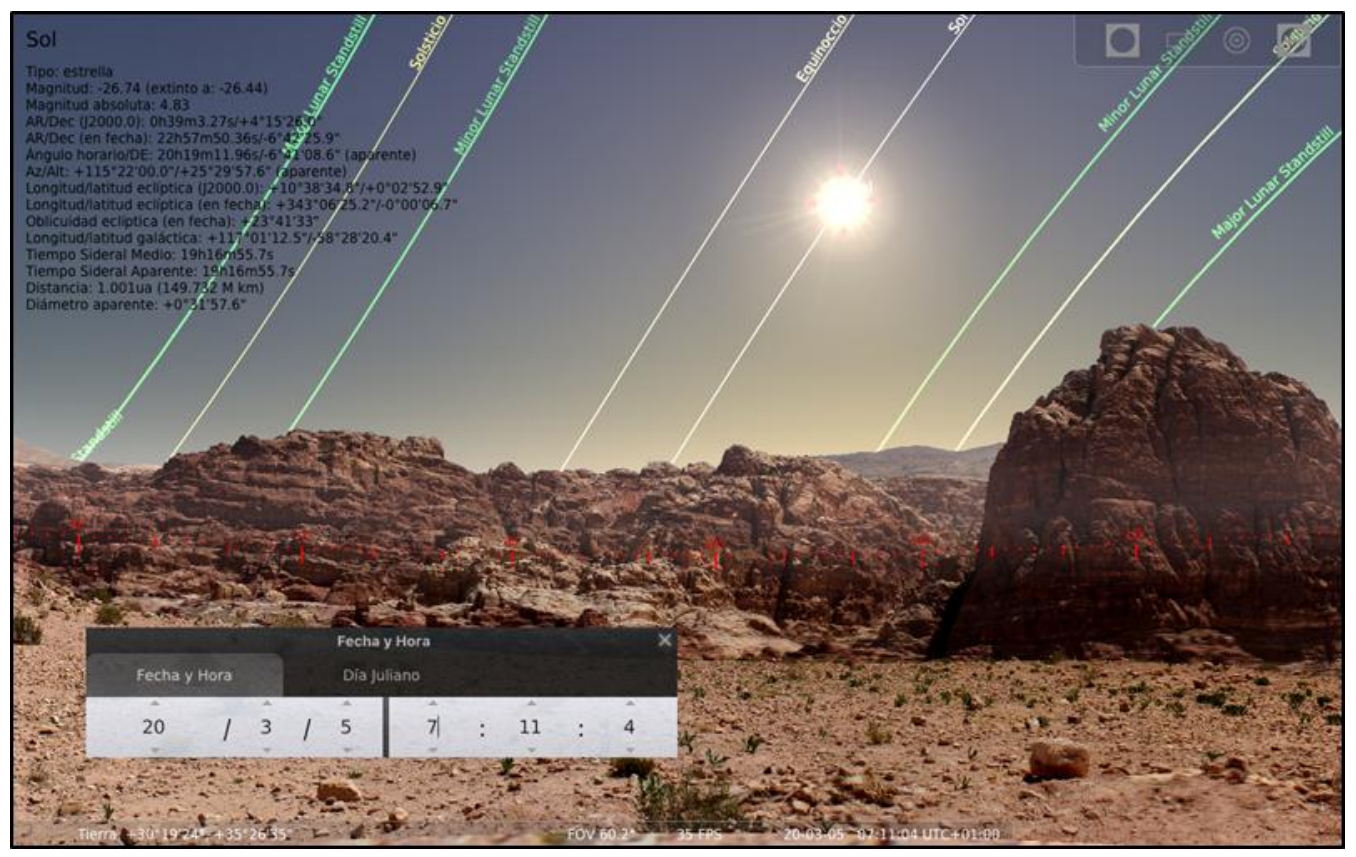

Figure 3. With the help of a panoramic picture properly referenced we can reconstruct the sky viewed in ancient times. The picture shows a panoramic reconstruction from the newly discovered cultic platform in Petra (Jordan) that has been incorporated into Stellarium to replicate the sky appearance at the epoch of use. (C) A.C. González-García.

Another way to do this landscape reconstruction implies having a good geo-referenced positioning of the site and employing geographic information systems (GIS) to reconstruct the horizon. This is useful not only for those cases when a $360^{\circ}$ photograph of the site is not available, but also for those where vegetation or buildings hamper the visibility of the sites. These can incorporate for instance data from LiDar flights. Indeed, the resolution of the digital terrain model (DTM) is the main problem to solve as it will dictate the uncertainty in the potential astronomical links of the sites investigated (see [12] for a recent use of this technique).

Of course, a kind of data that can be used is that derived from Geo-Radar and other geo-physical explorations of potential sites. In this case, the data can also be put into context of the landscape inspection and then derive orientation measurements and potential astronomical connections to those sites. One example of this kind of research has been carried out with a series of the circular enclosures in southern Portugal [21].

Finally, we should not forget the data acquisition techniques where we can take into account the $3 \mathrm{D}$ reconstruction of built structures. Those can then be incorporated into DTMs and planetarium models to investigate, verify and discover potential astronomical relations of light and shadow effects $([13,22,23]$, see Figure 4).

One key issue with the sustainability of data acquisition is the replicability of the research. This implies taking care of performing reliable estimates for our data (including errors), and a comprehensive description of the methodology employed and the sites measured.

One fundamental question we must carry out from this enumeration, regarding the sustainability of this kind of research, is that as the methodology does not imply altering the sites, this kind of measurements can be performed without (much) impact to already existing heritage sites. Besides it 
provides new data that normally have not been taken into account before and thus complements and expands our understanding of these sites and helps to bring new heritage into knowledge.

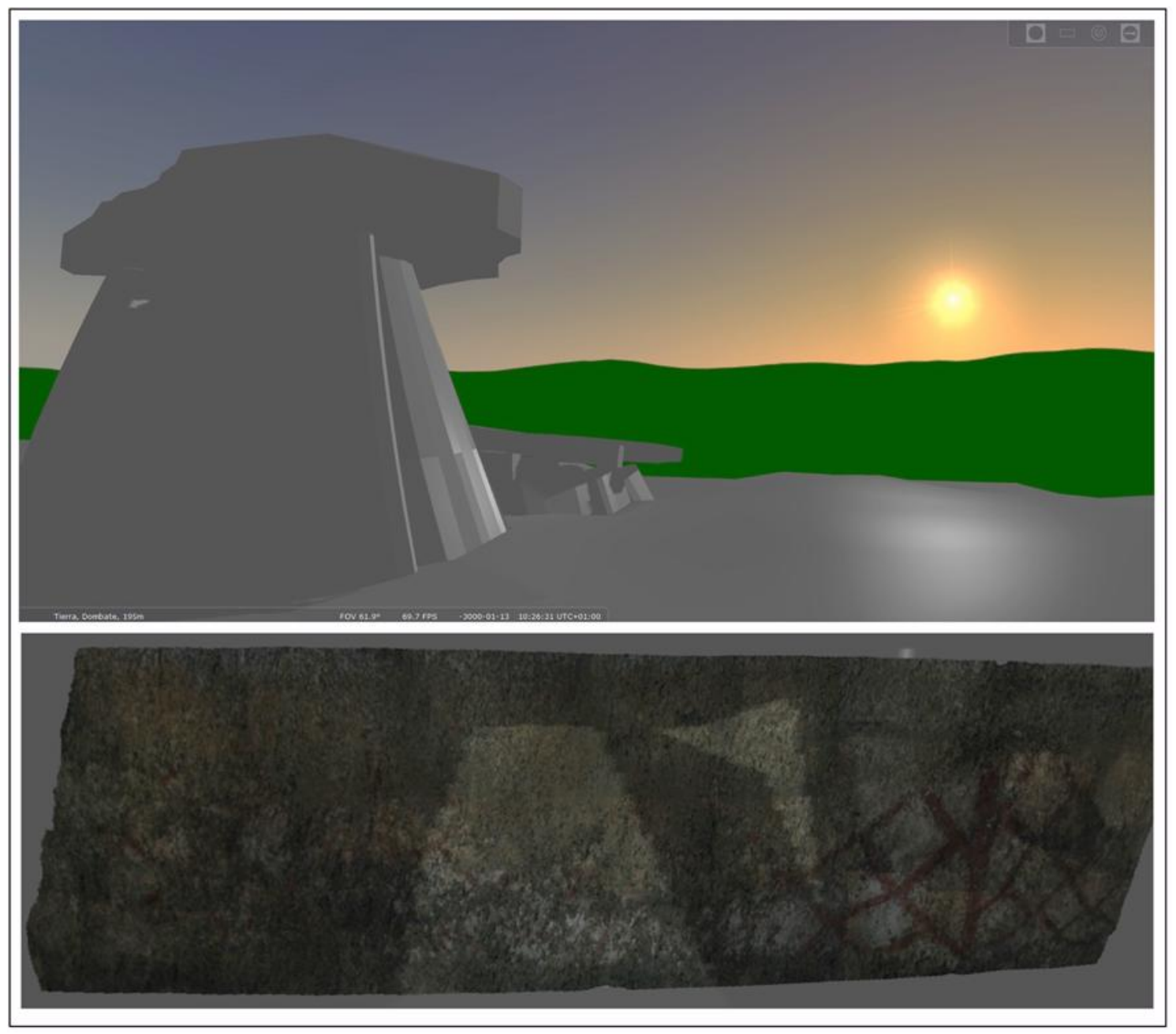

Figure 4. A 3D reconstruction of the dolmen of Dombate (A Coruña, Spain). Top: The 3D rendering has been included within a digital terrain model into the Stellarium software allowing investigation of the illumination of the paintings inside the megalithic chamber today precluded by the preservation measures of the dolmen. Bottom: The backstone of the dolmen, possibly the first to be erected at the time of construction, displays an elaborate program of decoration with sophisticated geometric forms, which are directly illuminated by the first sunbeams of the winter solstice. The 3D reconstruction allows verifying that the illuminated part never reaches further up than the area with red paintings. (C) A.C. González-García.

Nowadays, there is a rather well established methodology that shows that this discipline can be fully incorporated into the humanities as a useful tool to understand human past. In parallel there is an on-going substantial effort to upgrade the methodology by incorporating new techniques as well as new epistemological discourses.

In this sense, cultural astronomy studies in general and in particular those of archaeoastronomy are closely connected to the spatial and landscape dimension. Such connection links archaeoastronomy to the social aspect of the landscape. Thus, space is socially and culturally built. A number of variegated disciplines highlight that a 'landscape' is a created reality by social action. This can be found in different social disciplines such as human geography [24,25], anthropology [26-29], archaeology [30,31] and the history of religions [32-34]. 
From this point of view, archaeoastronomy is a key element for understanding and complementing our knowledge on the social construction of space and, given the recurrent and cyclical nature of the astronomical events, also the time and temporal dimension of these landscapes.

In a recent paper, Kristiansen [35] argues that while the objectivist ideal of procesualism has been long time set aside, it is also evident that the subjectivist version of post-procesualism or the hermeneutic liberalism are not the solution either. The enhancement of critic reflexivity as a central component of all theories and practices, and the consolidation of a weak or soft model of science (with rigorous data, robust methodologies and reflexive theories: R3 science), paves the way to new proposals that Kristiansen exemplifies with his "new paradigm" for archaeology.

His proposal combines the science-based potential of the archaeological investigation (big data, profound archaeometries, information sciences and visualization techniques) with solid theories to produce significant narratives, as a way to merge the point of view of anthropology, and humanities in general, with that of the 'hard' sciences.

In our understanding, cultural astronomy, given the characteristics presented above, is well positioned to face such integration also taking care of the sustainability of the research. The use of massive empirical datasets, together with the use of innovative visualization techniques (like 3D modeling of buildings inserted in a planetarium software) integrated in more solid theories, allow constructing narratives that provide an integrative and holistic sense to the social study of the sky.

In the following pages we will show how such an endeavor can be exemplified in one case study, the group of Romanesque Churches of the valley of Bohí (Lleida, Spain). Finally, we will present how this endeavor can help in the promotion of heritage sites, taking the high mountain sanctuaries and complexes in the central part of the island of Gran Canaria as an example.

\section{Cultural Astronomy in Action: Vall Bohí Medieval Churches}

It should be useful to include the description of a case study, where a series of sites can be sampled, in order to illustrate the aforementioned issues. In this sense, we present in this section a site where the local landscape, the distant horizon and the skyscape could interact, but at the same time would allow preserving the spirit of cultural astronomy as a sustainable discipline which respects the environment.

Located at the foothill of the Pyrenees, the secluded and beautiful Bohí Valley gained a significant relevance from the 9th century onwards. After the Muslim conquest of the Iberian Peninsula, some Christian counties were formed at the valleys of the Pyrenees with the support of the Carolingian kings. Apparently, the local feudal lords of this area received a significant amount of money to support the conquest of Saragossa and other nearby populations and they used such income for building a number of churches between the 11th and 12th centuries [36].

Nine of them remain in the area, all of them built in a Romanesque style with strong Lombard influences. They present elegant mason work and tall and stylized towers and the interior is frequently decorated with elaborate paintings (see Figure 5). These characteristics and their excellent state of preservation granted their inclusion in the UNESCO's World Heritage List in 2000.

According to the canonical medieval sources, the orientation of a church should be such that the apse must be facing towards east, and in particular at the equinox as defined in the Nicaea's Concilium [37]. In previous studies we have verified that, for the Iberian Peninsula, and for the period right before the introduction of the Romanesque style, such a definition is somewhat ambiguous. Pre-Romanesque churches in the Iberian Peninsula are vastly located in the northern half of the Peninsula and are normally facing a few degrees north of equinoctial east [38]. This can hardly be explained by an orienting method where the shadow of a gnomon is used to obtain the orientation of the church. However, a direct observation of sunrise on a given day and the use of the Julian calendar could be a likely explanation. Both the alleged day of the equinox, March 21st, or March 25th, a prominent Christian feast, would move with time as the Julian calendar shifted with respect to the seasons. One interesting exception to the norm for the Iberian Peninsula was found in the Serrablo Valley, where most churches (dating from the 10th century) are facing east but slightly south, instead of 
north, of the equinox [38]. Serrablo is not far from Bohí (c. $90 \mathrm{~km}$ as the crow flies), and those churches could perhaps be understood as the direct precedents of these ones in Bohí.

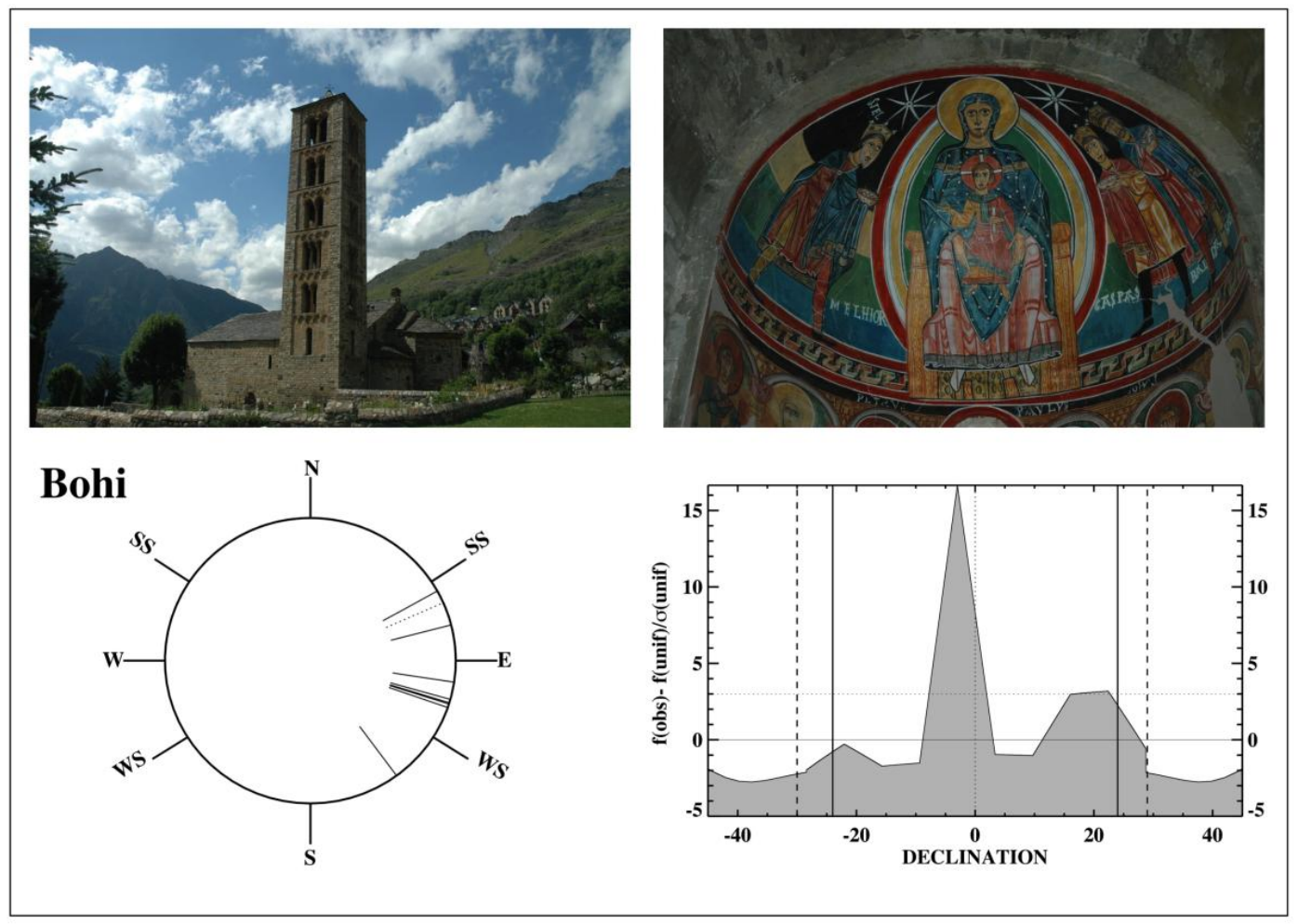

Figure 5. Top-left, Sant Climent de Taül, at Vall Bohí, is a wonderful example of the Romanesque churches in this mountainous area. Frequently the interior is decorated with magnificent paintings, often depicting astronomical symbolism associated to the Christian cult, such as in Santa María de Taül (top-right). The bottom-left panel shows the orientation diagram for the 10 churches presented in Table 1. Each measurement is plotted as a short stroke inside the circle. The strokes outside the circle indicate the cardinal points and the rise and set of the sun at the solstices for the latitude of the valley. However, this diagram does not take into account the altitude of the horizon, which at this alpine area is quite significant. To account for it, the declination histogram is presented in the bottom-right panel. It shows that, despite the azimuths being mostly towards several degrees south of east, the altitude of the horizon renders the orientations of a significant set of churches closer to equinoctial dates. (C) J.A. Belmonte and A.C. González-García.

Table 1. Orientation data for the nine churches in Vall Bohí, plus one in Andorra (Sta. Coloma). Columns indicate the church name, azimuth as measured towards the church apse, the altitude of the horizon in that direction and the astronomical declination. The mean latitude of the valley is $42^{\circ} 30^{\prime}$ North.

\begin{tabular}{cccc}
\hline Church & $\mathbf{a}\left(^{\circ}\right)$ & $\mathbf{h}\left(^{\circ}\right)$ & $\delta\left(^{\circ}\right)$ \\
\hline Sta. María de Taüll & 107.7 & 15 & -2.4 \\
S. Climent de Taüll & 107.7 & 14 & -3.1 \\
S. Joan de Bohí & 143.7 & 14 & -24.4 \\
Sta. Eulalia de Erill la Vall & 107.2 & 10.5 & -5.3 \\
La Nativitat de Durro & 109.2 & 19 & -0.6 \\
S. Feliu de Barruera & 98.7 & 19 & 6.6 \\
Sta. María de Cardet & 105.75 & 14.5 & -3.6 \\
La Assumpció de Cóll & 60.75 & 14.5 & 31.1 \\
S. Joan de Caselles & 75.5 & 7 & 15.3 \\
Sta Coloma, Andorra & 66 & 6.5 & 21.9 \\
\hline
\end{tabular}


In summer 2011, nine churches in the area included in the UNESCO list (plus Santa Coloma in Andorra la Vella) were measured in a field campaign. Their data are included in Table 1. Measures were obtained using a Silva Survey Master tandem with a professional compass plus a clinometer. Thus, the accuracy of a single measurement can be estimated to be of $\frac{1}{4}^{\circ}$ in azimuth and $\frac{1}{2}^{\circ}$ in altitude of the horizon, this translates into roughly $\frac{3}{4}^{\circ}$ in astronomical declination. No single rock or terrain area was moved when taking the measurements. These where corrected for magnetic declination employing the Enhanced Magnetic Model (EMM) found on the National Geophysical Data Center (NGDC) website (https://www.ngdc.noaa.gov/geomag-web/), the latitude was obtained with a hand-held GPS and astronomical declination was calculated employing our own software including a correction for atmospheric refraction [39].

Figure 5 shows that all churches were facing the east horizon, and all but one were inside the solar limits. In particular, the inspection of Table 1 and the declination histogram in Figure 5 shows that a good number of them were facing slightly south of the equinox, by averaging $-3^{\circ}$ in declination (above $15^{\circ}$ in azimuth). Interestingly, the $14^{\circ}$ of altitude of the close horizon at Sant Joan de Bohí corrects for the $143 \frac{3}{4}^{\circ}$ azimuth permitting, within the errors, a winter solstice alignment for this church, devoted to Saint John the Evangelist whose feast ranks close to the winter solstice, precisely. This was a rare phenomenon in the Iberian Peninsula in those distant epochs.

Another interesting consequence is that these churches seemed to comply with the norm found in the Serrablo valley, as explained early on. This could be due to the difficulty in building and properly orienting the churches in these alpine valleys with very close and abrupt horizons. However, the fact that both groups were close but not in direct contact (c. $90 \mathrm{~km}$ of rough land straddle them) poses an interesting problem and opens the possibility that for both groups the persistence of such orientation, slightly south of due east, may point to intentionality (perhaps similar dates for sunrise along the year).

Despite being part of different feudal territories (Counties of Aragon and Ribagorza, respectively) both were at the time dependent on the Frank kings and perhaps, given the difference with the orientation found in the contemporary churches of other parts of the Iberian Peninsula, the link should perhaps be sought for at the other side of the Pyrenees. This is something for further exploration in future research.

\section{The Canarian Paradigm}

Cultural astronomy studies, including both ethno- and archaeoastronomy, have now a tradition of a quarter century in the Canary Islands. The statistical relevance of astronomical implications for a certain number of sites and the spectacular character of some of the findings clearly points out to intentionality in the astronomical relationships discovered so far. There are two paradigms where this relationship is, besides, clearly related to sustainability issues: The mountain of Tindaya, in the island of Fuerteventura, and the 'Risco Caído and the sacred mountains of Gran Canaria Cultural Landscape'.

One of the earliest substantial discoveries in the islands was the probable astronomical connection of the aboriginal footprint engravings (usually called podomorphs) of Montaña Tindaya, a singular mountain dominating the northern plains of the semi-desert island of Fuerteventura (see Figure 6). Tindaya was a local reference of certain importance for ethnographic studies and also an important archaeological site where the largest sample of podomorphs in the world could be found. The mountain was also the centre of a series of aboriginal archaeological sites with obvious religious implications (Figure 6).

However, all these important issues were not enough to save the mountain from wild modern building speculation. Tindaya actually is the nucleus of an eroded volcanic cone formed by an appealing and beautiful stone called trachyte. Hence, a series of quarries were open in the skirts of the mountain, which could, eventually, have destroyed it completely (see e.g., Figure 1). In the mid 1990s, a team led by the archaeologist María Antonia Perera decided to include Tindaya and its podomorphs in a project where cultural astronomy would play the most relevant role to revalue the mountain and its environment. Despite some misfortune initiatives which tried to make a putative use of the results, 
such as the bizarre idea of making an 'insculpture' inside the mountain, the project was certainly successful [40].

The data showed that these petroglyphs, counted by hundreds, do not follow a random pattern but rather they have a clear custom of orientation with a concentration in the W-SW sector of the horizon (see Figure 7). Different hypotheses have been offered for this pattern and the visibility of the Peak of Teide in the distant island of Tenerife is perhaps among the most suggestive (see Figure 8). Teide, a huge volcanic cone $3714 \mathrm{~m}$ high, has been interpreted as a sort of axis mundi for the aboriginal populations of the Canary Islands because it is visible from all of them and it should have been really impressive either at daylight when covered by snows or at night when in an eruptive process. However, it cannot explain the whole sample alone.

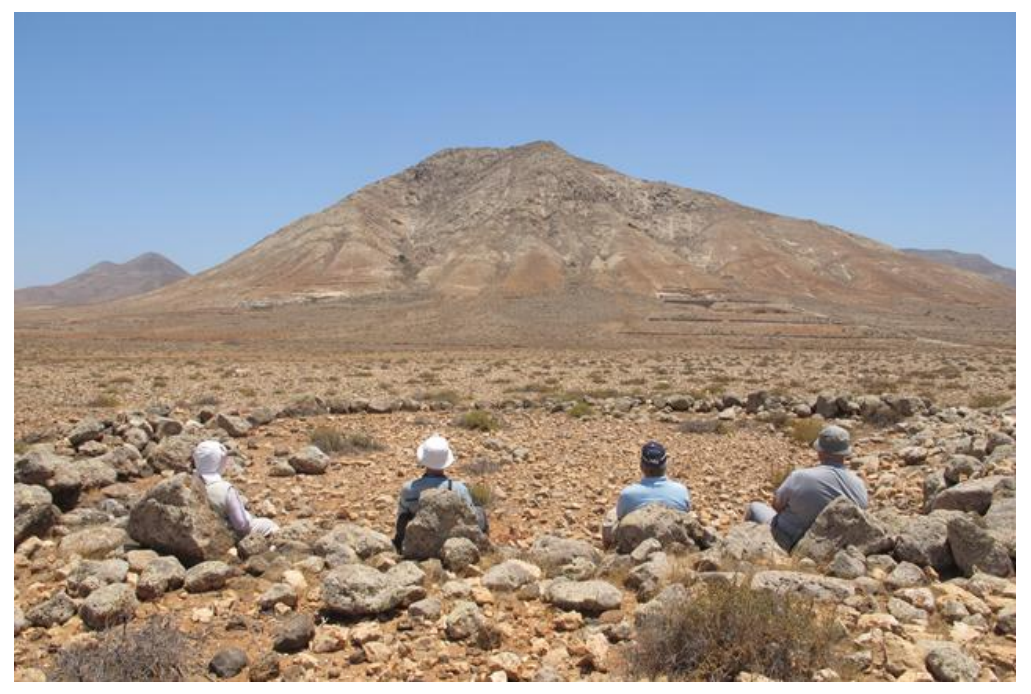

Figure 6. Montaña Tindaya, in Fuerteventura, as seen from the ancient 'esequen' (stone circle) of Llano del Esquinzo. The southern (right) peak is virtually full of footprint engravings (podomorphs) with a non-random orientation pattern. Researchers are seated in cyclopean chairs facing the mountain. (C) J.A. Belmonte.

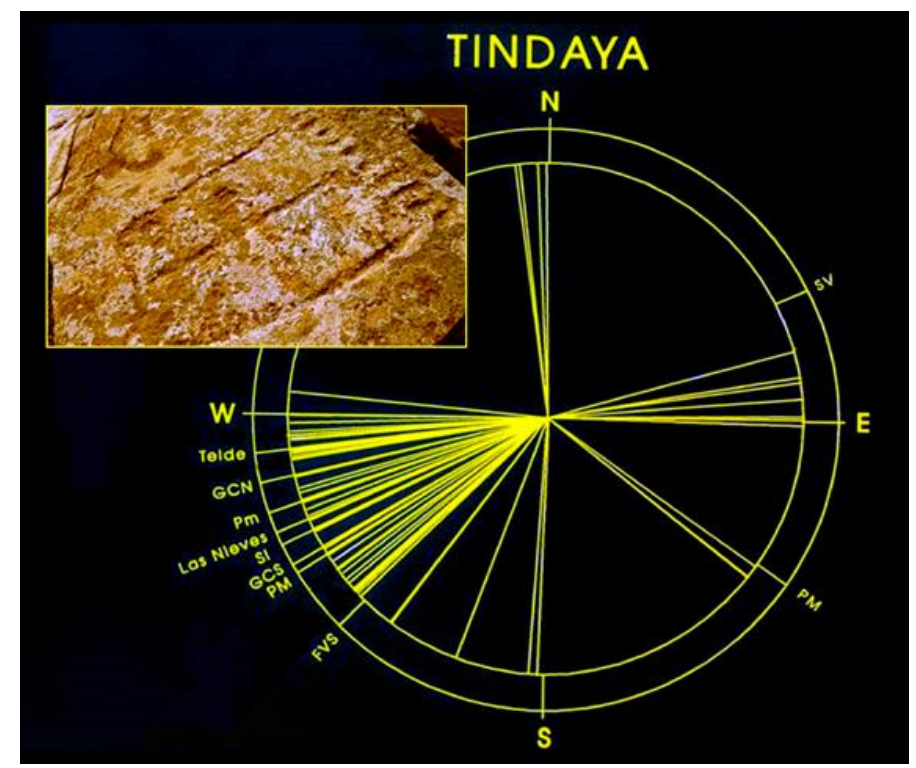

Figure 7. Orientation diagram of the podomorphs of Tindaya (see inset of a pair of footprint engraving), showing several topographical and astronomical references, including the winter solstice sunset (SI) and southern moon standstills (PM for Major Standstill and Pm for Minor Standstill). (C) M.A. Perera, J.A. Belmonte and C. Esteban. 


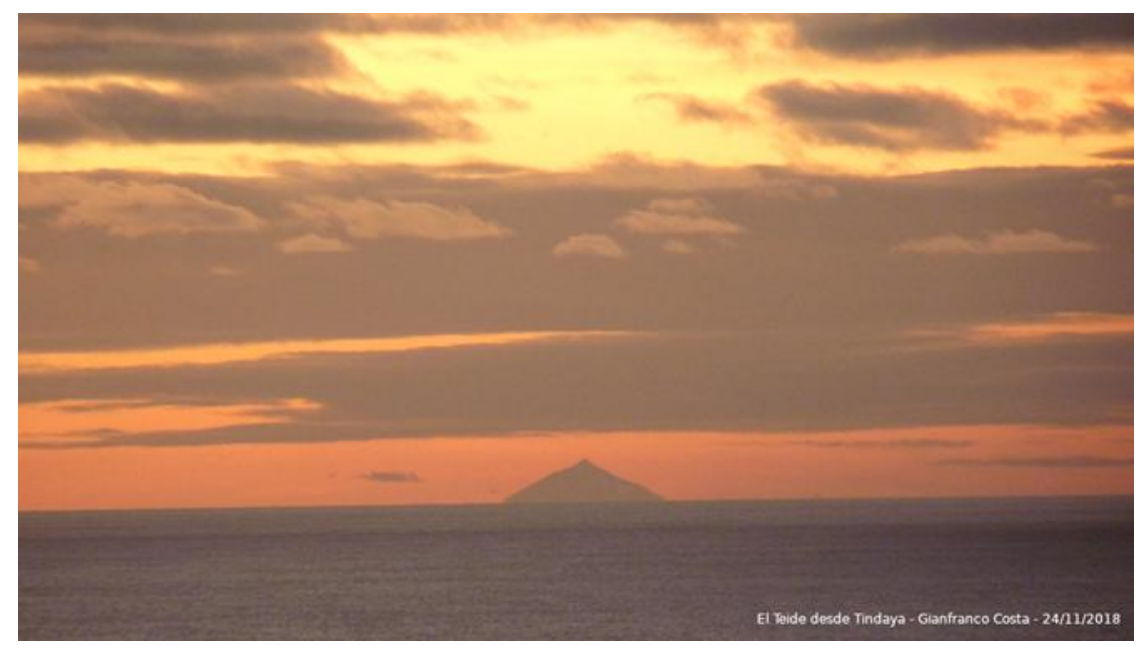

Figure 8. Teide peak in faraway Tenerife Island, the axis mundi of many populations of the archipelago, as seen from Tindaya in Fuerteventura. This could be a topographic reference for orienting the podomorphs. (c) Gianfranco Costa.

Currently, the most suggestive hypothesis of all is the one postulating a relationship with the epoch of maximum rainfall in the island in the period from late November to late December and the vision of Venus as the evening star in combination with the crescent moon closest to the winter solstice [41]. Present day peasants and goatherds in Fuerteventura and other islands have interpreted the visibility and behavior of Venus as the evening star in this period of the year as a water carrier. Hence it could have been related to fertility cults in pre-Hispanic times [42]. As a matter of fact, cultural astronomy studies, without the need to alter the terrain and only looking at the horizon and the sky, have been able to reinforce the value of Tindaya, preserving the mountain for future generations in a sustainable way.

On the other hand, the island of Gran Canaria (see Figure 9) presented the most evolved and richest pre-Hispanic culture of the Canary Archipelago. The population had, as for each of the other islands, an undoubted proto-Berber ancestry, which lasted from the turn of the era to the Castilian conquest in $1483 \mathrm{AD}$. The social structure was complex and hierarchical, similar to a proto-state. This island is characterized by the presence of sanctuaries at the top of significant mountains and on the scarps of the huge volcanic calderas of the island, which are often called 'almogaren' thanks to the early chronicles, where particular rituals took place at precise moments of the year [43].

In particular, the area of the Caldera de Tejeda (Figure 9) presents a paradigmatic example of an adaptive process to a harsh but attractive environment, offering an excellent horizon. This includes impressive natural monuments such as the Roques Bentayga and Nublo, acting as reference landmarks where land- and skyscapes could be in close contact and permanent interaction (see Figure 10). This chain of facts suggested it as the perfect location for a cultural landscape which might be defended within the framework of UNESCO and the International Astronomical Union (IAU) Astronomy and World Heritage Initiative [6] under the name: 'Risco Caído and the sacred mountains of Gran Canaria' [44]. Risco Caído was the name of one of the most representative sites used as a sort of brand.

The area of the cultural landscape is impressive, including the Tejeda Basin and the Ravine of Barranco Hondo (where Risco Caído is located; see Figure 11). These are areas of the summit of Gran Canaria that have been inhabited since antiquity to the present day and where the local population had to make a huge adaptive effort to a not easy environment, applying sustainable practices before the word was even defined.

The relatively high cultural level of the ancient Canarians or 'Canarios', a name later extended to the rest of the archipelago, is clearly illustrated by the existence of irrigated land agriculture, with the stock of the products in communal granaries such as the one of El Alamo in Mesa de Acusa, in the western border of the Caldera. Indeed, a lunisolar calendar ought to be developed to control time and 
the productive cycle [45]. A large number of petroglyph stations, including alphabetic inscriptions, have been reported in Gran Canaria. The examples of the artificial sanctuary caves at Risco Chapín and Risco Caido (inside the cultural landscape limits, Figure 9; Figure 10) with the largest collection of pubic triangles in the world, which could be interpreted within a fertility cult, are among the most relevant.

The recently discovered light and shadow effects at Risco Caído [46] are indeed a highlight within this particular context. In Gran Canaria, dedicated fieldwork strongly suggests that most of the high-mountain sanctuaries, often located at high spots dominating a wide, and sometimes, impressive panorama, could be related with solar and lunar observations and, certainly astral cults [47] since: "the Canarians are idolatrous, worshiping the Sun, the Moon and other Planets" (Alvise de Cadamosto, 15th century AD [48]), or " ... they worshiped fire, the Sun and the Moon, and the Dog Star, when they started the year with grand feasting ..." (Tomas Arias Marín de Cubas, 1694 [49]). The cultural landscape under examination within the property area includes a good sample of these relationships.

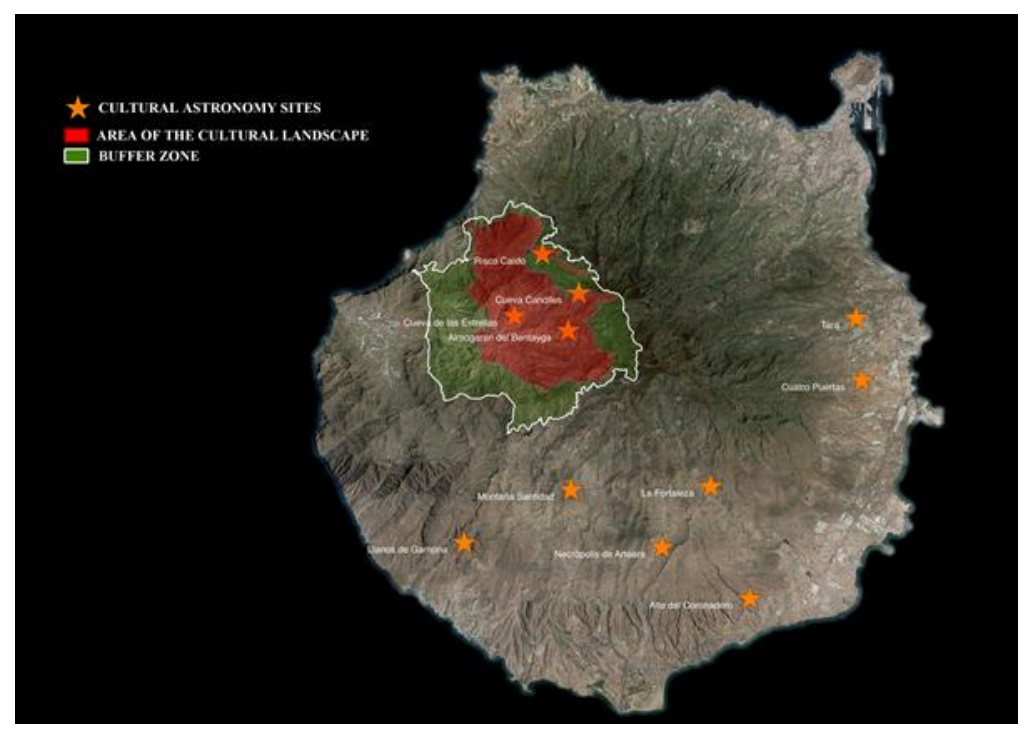

Figure 9. Star depicts settlements in Gran Canaria: Ancient Canarian sites where astronomy did play a most relevant role. Four of them, including some of the most important, are within the limits of the cultural landscape 'Risco Caído and the sacred mountains of Gran Canaria' (red color). This property corresponds to the best preserved and most sustainable area of the island. (C) Cabildo de Gran Canaria.

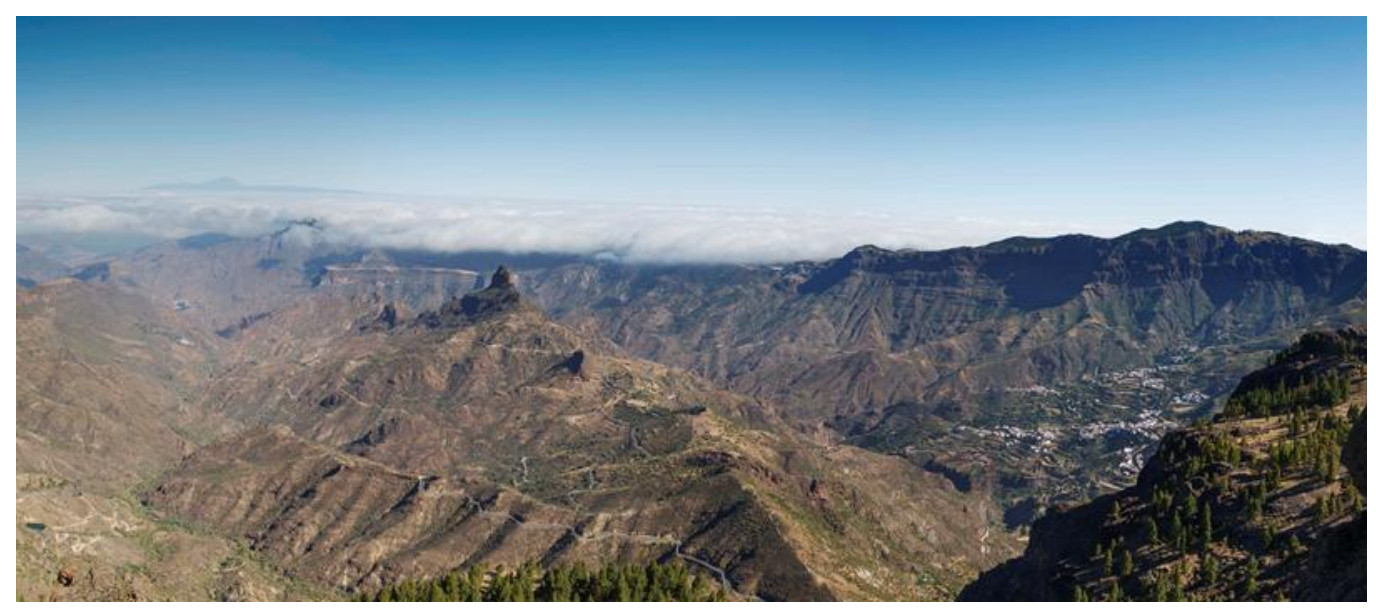

Figure 10. A general view of the Tejeda Basin, the nucleus of the cultural landscape, as seen from the base of Roque Nublo (Figure 12). It is dominated by Roque Bentayga (centre left) and Risco Chapín to the right. This is a nearly perfect example of an interacting land- and skyscape. Tenerife, with Teide, is seen in the distance, to the left above the clouds. (C) Cabildo de Gran Canaria. 


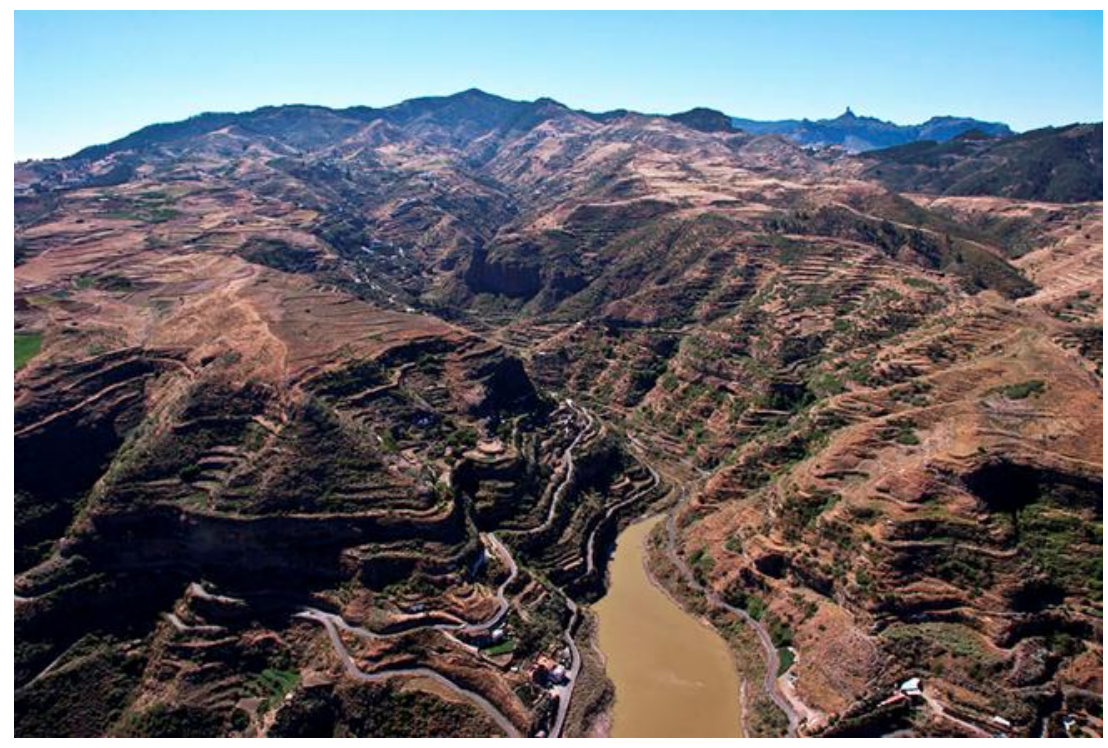

Figure 11. Barranco Hondo Ravine, the ancient sector presumably named Artevigua in the chronicles, where the sanctuary of Risco Caido is located. This is a perfect example of sustainability applied to a harsh environment. Roque Nublo is seen in the distance. (C) Cabildo de Gran Canaria.

To handle with the initiative and defend the importance of the property in front of UNESCO evaluating panels (notably the International Council of Monuments and Sites, ICOMOS), a multidisciplinary international team of specialists was created, including archaeologists, anthropologists, botanists, architects, geologists, environmental experts, developing managers and, indeed, cultural astronomers (see Figure 12). Within this framework, 'Risco Caído and the sacred mountains of Gran Canaria' initiative has been considered as an excellent laboratory where the close relationship between land- and skyscapes in human culture can be illustrated. The idea is to prove that the area selected within the island (Figure 8) is a paradigm as a marvelous example of a cultural landscape worth being declared as a World Heritage Site. In this line of argument, the following outstanding universal value (or OUV in UNESCO jargon) criteria have been settled in the proposal (Astronomically relevant issues are highlighted in bold face):

Criterion (iii): "The ensemble of archaeological sites constitutes a unique and exceptional testimony to an extinct island culture that evolved in isolation for a period of more than one thousand five hundred years. Archaeological evidence and documentary sources relative to the proposed property bear witness to the fact that this culture dates back to the first settlers that arrived to these shores from the Berber Maghreb, which in itself is outstanding, as this thus constitutes a unique case of an island culture with roots in the pre-Islamic Amazigh world, manifestations of which are few and far between. The place expresses a very strong and very original relationship of human beings with nature (both Earth and Sky). The proposed property constitutes an outstanding testimony to an island culture that integrates the skyscape as a fundamental part of its worldview, its rituals and beliefs, and which has also developed its own astronomical culture in close harmony with the natural environment and the surrounding landscape. Clear evidence of this is the astronomical sanctuaries, such as Risco Caído that represent the pinnacle of the evolution of this knowledge and practices. This legacy illustrates the odyssey of the indigenous island cultures of the planet that have evolved over long periods without outside influence, ultimately creating their own cosmology and a unique world of knowledge and beliefs". And:

Criterion (v): "The indigenous troglodyte settlements of Caldera de Tejeda and the surrounding area constitute an inimitable example of this type of human habitat in ancient island cultures, illustrating a level of organization of space and adaptive management of resources that is highly efficient and complex. The extensive geological backdrop and the natural landscapes fuse with the cave settlements, sanctuaries, sites and terraces, developing a unique culture that still maintains its 
principal references, as well as its symbolic and cosmological connotations. This type of human settlement has survived through history, creating new ways of occupying the space that express the syncretism between the indigenous culture and the new culture established after the Spanish conquest. The survival of techniques and ancestral land uses, such as transhumance, should also be added to this. The orientation and alignment of certain sanctuaries and artificial caves also indicate the intimate relationship that this type of settlement has with the skyscape and the principal symbolic elements of the landscape. Spatial distribution of the settlements and the archaeological finds give us an in-depth understanding of how indigenous people used the territory of the sacred mountains. The areas surrounding the sites contain habitats and species of flora and fauna that also inform us on the way of life of the early settlers. Knowledge of the skills and cultural traditions of the indigenous settlers on the island has been definitively changed as a direct consequence of the new evidence provided by this incomparable territory".

Hence in Gran Canaria, and notably in the area of the property, a paradigmatic example of the interaction between topography and the sky is found; a paradigm which cultural astronomy has helped to disentangle. The comparative analysis made for the memory [50] suggests that there is no other site in the world where such a combination is so clearly illustrated although parallelisms could be found with Rapa Nui or Thebes in Egypt, but not in such a gigantic and outstanding scale as here.

Hence aspects like relations between astral divinities, seasonal cycles, the need to measure time or fertility worship with its rock-art symbols, is highlighted in the different pieces of evidence that illustrate the cosmology held by the ancient inhabitants of the Canary Islands.

Although it is true that an intrinsic relationship cannot be proven entirely, the evidence is suggestive and talks about a people who were able to adapt to a harsh environment that we researchers are obliged to keep today. In any event, it is not a question of interpreting an entire cultural context in accordance with the sky, just as it would be a serious mistake to forget about it.

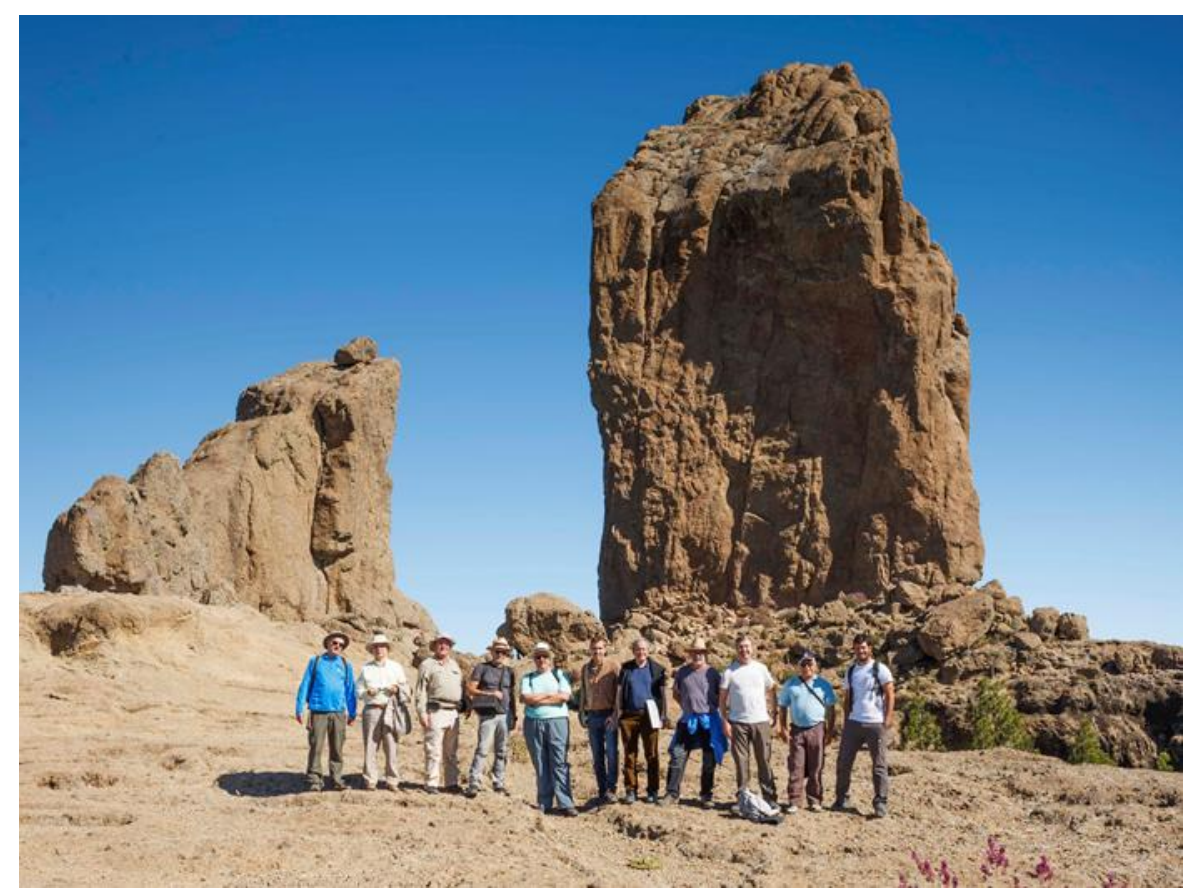

Figure 12. Part of the team of scholars supporting the initiative of a UNESCO cultural landscape in Gran Canaria summit in front of Roque Nublo. The group is formed by archaeologists, anthropologists, botanists, architects, geologists, environmental experts and, indeed, cultural astronomers. (C) Cabildo de Gran Canaria. 


\section{Conclusions}

To conclude, we would like to highlight once again that cultural astronomy is thus a discipline with a sustainable methodology that helps identifying new heritage or provides new value to already existing heritage or, finally, helps identify heritage at risk.

As a relatively new discipline, cultural astronomy accumulates new observations and points of view on different geographic areas, historic periods and subjects. Cultural astronomy allows us to grasp the worldview of past and ancient societies. Besides, it gives new sense to the archaeological and cultural heritage.

A further point that should be mentionehere is that cultural astronomy has a clear social educative value both to present the value of astronomy in ancient societies [51] or for actually teaching astronomy to present day students [52].

Finally, and as far as it engages with society to promote new initiatives, we can ensure the sustainability of the research. However, cultural astronomy also makes society aware of the importance of the sky for our past. Hence, it can help in promoting a sustainable use of the sky, for instance by promoting the use of particular luminaries at heritage sites where the sky is important for the apprehension of the past intent of the builders of ancient sites. The Starlight Initiative [53], and its strong cultural aspects, would be a good example of this.

Author Contributions: Conceptualization, A.C.G.-G. and J.A.B.; Writing—original draft preparation, A.C.G.-G. and J.A.B.; Writing — review and editing, A.C.G.-G. and J.A.B.

Funding: This work was partially supported by the projects P/310793 'Arqueoastronomía' of the IAC, and AYA2015-66787 'Orientatio ad Sidera IV' of the Spanish MICIU.

Acknowledgments: We would like to thank Prof. Ioannis Liritzis for the invitation to produce this work. The authors would especially like to thank Gianfranco Costa, Cipriano Marín and the Gran Canaria Council for some of the beautiful images illustrating this paper

Conflicts of Interest: The authors declare no conflict of interest.

\section{References}

1. Iwaniszewski, S. Por una astronomía cultural renovada. Complutum 2009, 20, 23-38.

2. Krupp, E.C. Archaeoastronomy. In History of Astronomy, an Encyclopedia; Lankford, J., Ed.; Routledge: New York, NY, USA, 1997; pp. 21-30.

3. García Quintela, M.V.; González-García, A.C. Arqueoastronomía, Arqueología y Paisaje. Complutum 2009, 20, 39-54.

4. Criado, F. Arqueológicas: En Busca de la Razón Perdida; Bellaterra: Barcelona, Spain, 2012; p. 23.

5. Castro, B. A historical review of the Egyptian calendars: The development of time measurement in ancient Egypt from Nabta Playa to the Ptolomies. Sci. Cult. 2015, 1, 15-27.

6. Ruggles, C.L.N.; Cotte, M. (Eds.) Heritage Sites of Astronomy and Archaeoastronomy in the Context of the UNESCO World Heritage Convention: A Thematic Study; ICOMOS-IAU: Paris, France, 2010.

7. Ruggles, C.L.N. (Ed.) Heritage Sites of Astronomy and Archaeoastronomy in the Context of the UNESCO World Heritage Convention: Thematic Study no. 2; ICOMOS-IAU: Paris, France, 2017.

8. Belmonte, J.A.; González García, A.C.; Polcaro, A. On the orientation of megalithic monuments of the Transjordan plateau: New clues for an astronomical interpretation. J. Hist. Astron. 2013, 44, 429-455. [CrossRef]

9. Nature on Sustainability. Available online: https//www.nature.com/subjects/sustainability (accessed on 6 March 2019).

10. Prendergast, F. Techniques of Field Survey. In Handbook of Archaeoastronomy and Ethnoastronomy; Ruggles, C.L.N., Ed.; Springer: New York, NY, USA, 2015; pp. 389-410.

11. Ruggles, C.L.N.; Martlew, R.D. The North Mull Project (3): Prominent Hill Summits and their Astronomical Potential. Archaoastronomy 1992, 17, S1-S13. [CrossRef]

12. Higginbotton, G.; Clay, R. Origins of Standing Stone Astronomy in Britain: New Quantitaive Techniques for the Study of Archaoastronomy. J. Archaol. Sci. Rep. 2016, 9, 249-258. 
13. González-García, A.C.; Criado-Boado, F.; Vilas Estévez, B. Megalithic Skyscapes in Galicia. Cult. Cosmos 2017, 21, 87-103.

14. González-García, A.C.; Belmonte, J.A. Thinking Hattusha: Astronomy and landscape in the Hittite lands. J. Hist. Astron. 2011, 42, 461-494. [CrossRef]

15. Belmonte, J.A. Pirámides, Templos y Estrellas; Crítica: Madrid, Spain, 2012.

16. Liritzis, I.; Bousoulegka, E.; Nyquist, A.; Castro, B.; Alotaibi, F.M.; Drivaliari, A. New Evidence from archaeoastronomy on Apollo oracles and Apollo-Asclepius related cult. J. Cult. Herit. 2017, 26, 129-143. [CrossRef]

17. Rodríguez Antón, A.; González-García, A.C.; Belmonte, J.A. Astronomy in Roman Urbanism: A Statistical Analysis of the Orientation of Roman Towns in the Iberian Peninsula. J. Hist. Astron. 2018, 49, 363-387. [CrossRef]

18. Ruggles, C.L.N. Astronomy in Prehistoric Britain and Ireland; Yale University Press: New Haven, CT, USA, 1999.

19. Hoskin, M. Tombs, Temples and their Orientation; Ocarina Books: Bognor Regis, UK, 2001.

20. Zotti, G. Open-source virtual archaeoastronomy. Mediterr. Archaeol. Archaeom. 2016, 16, 17-24.

21. Gómez, J.; Mejuto, M.; Rodríguez, G. Generación de una capa astronómica para la IDE arqueológica. Arqueoastronomía en el sur de Portugal. Rev. Catalana Geogr. 2012, 17, 44.

22. González-García, A.C.; Vilas-Estévez, B.; López-Romero, E.; Mañana-Borrazás, P. Domesticating Light and Shadows in the Neolithic: The Dombate Passage Grave (A Coruña, Spain). Camb. Archaeol. J. 2019, 29, 327-343. [CrossRef]

23. Vlachos, A.; Liritzis, I.; Georgopoulos, A. The lightning of the god's face during solar stands in the Apollo temple Delphi. Mediterr. Archaeol. Archaeom. 2018, 18, 225-246.

24. Sitwell, O.F.G.; Latham, G.R. Behavioural Geography and the Cultural Landscape. Geogr. Annaler. Ser. B Hum. Geogr. 1979, 61, 51-63. [CrossRef]

25. Tuan, Y. Language and the Making of Place: A Narrative-Descriptive Approach. Ann. Assoc. Am. Geogr. 1991, 81, 684-696. [CrossRef]

26. Santos-Granero, F. Writing History into the Landscape: Space, Myth, and Ritual in Contemporary Amazonia. Am. Ethnol. 1998, 25, 128-148. [CrossRef]

27. Raffles, H. Local Theory: Nature and the Making of an Amazonian Place. Cult. Anthropol. 1999, 14, 323-360. [CrossRef]

28. Hayden, R.M. Antagonistic Tolerance. Competitive Sharing of Religious Sites in South Asia and the Balkans. Curr. Anthropol. 2002, 43, 205-231. [CrossRef]

29. Holtzman, J. The Local in the Local. Models of Time and Space in Samburu District, Northern Kenya. Curr. Anthropol. 2004, 45, 61-84. [CrossRef]

30. Ingold, T. The Temporality of the Landscape. World Archaeol. 1993, 25, 152-174.

31. Criado Boado, F. Del Terreno al Espacio; GIAP-U. de Santiago: Santiago, Spain, 1999.

32. Durkheim, É. Las Formas Elementales de la Vida Religiosa; Akal: Madrid, Spain, 1982.

33. Smith, J.Z. To Take Place; U. of Chicago Press: Chicago, IL, USA; London, UK, 1987.

34. Woodard, R.D. Indo-European Sacred Space; U. of Illinois Press: Urbana, IL, USA; Chicago, IL, USA, 2006.

35. Kristiansen, K. Towards a New Paradigm? The third Science revolution and its possible consequences in Archaeology. Curr. Swed. Archaeol. 2014, 22, 11-34.

36. Bellmunt Figueras, J. La Vall de Boí; Pagès Editors: Barcelona, Spain, 2017.

37. González-García, A.C. A voyage of Christian medieval astronomy: Symbolic, ritual and political orientation of churches. In Stars and Stones: Voyages in Archaeoastronomy and Cultural Astronomy; Pimenta, F., Ed.; BAR International Series: Oxford, UK, 2015; pp. 268-275.

38. González-García, A.C.; Belmonte, J.A. The Orientation of Pre-Romanesque Churches in the Iberian Peninsula. Nexus Netw. J. 2015, 17, 353-377. [CrossRef]

39. Schaeffer, B. Astronomy and the Limits of Vision. Vistas Astron. 1993, 36, 311-361. [CrossRef]

40. Perera Betancort, M.A.; Belmonte, J.A.; Esteban, C.; Tejera Gaspar, A. Tindaya: Un acercamiento arqueoastronómico a la sociedad prehispánica de Fuerteventura. Tabona 1996, 9, 163-193.

41. Belmonte, J.A.; Hoskin, M. Reflejo del Cosmos; Equipo Sirius: Madrid, Spain, 2002.

42. Belmonte, J.A.; Sanz de Lara, M. El Cielo de los Magos; La Marea: La Laguna, Spain, 2001.

43. Esteban, C.; Belmonte, J.A.; Schlueter, R.; González, O. Equinoctial markers in Gran Canaria Island, Parts I \& II. Archaeoastronomy 1996, 21, S73-S79. 
44. Belmonte, J.A.; Cuenca Sanabria, J.; Gil, J.C.; Marín, C.; de León, J.; Ruggles, C.L. The cultural landscape 'Risco caído and the sacred mountains of Gran Canaria: A paradigmatic proposal within UNESCO Astronomy and Wolrd Heritage initiative. Mediterr. Archaeol. Archaeom. 2018, 18, 377-385.

45. Belmonte, J.A.; Perera Betancort, M.A.; González-García, A.C. Calendario, signo y símbolo: Tres claves para una aproximación al poblamiento del Archipiélago Canario. In Homenaje a Antonio Tejera; Chaves, E., Ed.; Universidad de La Laguna: La laguna, Spain, 2019; pp. 118-141.

46. Cuenca Sanabria, J.; de León, J.; Marín, C.; Gil, J.C.; Belmonte, J.A.; Gil Sarmiento, C.; Márquez Zárate, J.M. The almogaren of Risco Caído: A singular astronomical sanctuary of the ancient Canarians. Mediterr. Archaeol. Archaeom. 2018, 18, 11-18.

47. Belmonte, J.A. Pre-Hispanic sanctuaries in the Canary Islands. In Handbook of Archaeoastronomy and Ethnoastronomy; Ruggles, C.L.N., Ed.; Springer: New York, NY, USA, 2015; pp. 1115-1124.

48. Cadamosto, A. Viagens de Alvise de Cadamosto e de Pedro de Sintra; Academia Portuguesa da Historia: Lisbon, Portugal, 1948.

49. Marín de Cubas, T.A. Historia de las Siete Islas de Canaria; Real Sociedad de Amigos del País de Las Palmas: Las Palmas de Gran Canaria, Spain, 1986.

50. de León, J.; Marín, C. (Eds.) Risco Caído and the Sacred Mountains of Gran Canaria Cultural Landscape; Cabildo de Gran Canaria: Las Palmas, Spain, 2018.

51. Hannah, R. The roles of observational astronomy in ancient Greece. Sci. Cult. 2015, 1, 47-56.

52. Pannou, E.; Violetis, A. Teaching astronomy using monuments of cultural heritage: The educational example of "horologion of Andronikos Kyrrhestes". Sci. Cult. 2018, 4, 77-83.

53. Starlight Initiative. Available online: https://fundacionstarlight.org/ (accessed on 6 March 2019).

(C) 2019 by the authors. Licensee MDPI, Basel, Switzerland. This article is an open access article distributed under the terms and conditions of the Creative Commons Attribution (CC BY) license (http://creativecommons.org/licenses/by/4.0/). 